\title{
STRUCTURE AND ELECTROLUMINESCENT PROPERTIES OF THIN TETRACENE LAYERS ON GOLD ISLAND FILMS
}

\author{
L. VIDUTA, T. GAVRILKO, A. MARCHENKO, V. NECHYTAYLO, \\ A. SENENKO, R. FEDOROVICH, P. SHABATYN
}

PACS 78.60.Fi, 68.55.-a

Institute of Physics, Nat. Acad. of Sci. of Ukraine

(C) 2012

(46, Nauky Prosp., Kyiv 03680, Ukraine)

The molecular structure, morphology, and electrical conductivity of thin tetracene layers obtained by the thermal vacuum deposition have been studied with the help of FTIR spectroscopy and STM/STS techniques as well. It has been shown that this preparation method does not change the tetracene molecular structure. The tetracene thin layers on the atomically smooth pyrolytic graphite surface demonstrate an amorphous structure. The local current-voltage characteristics (CVC) measured for tetracene films $\sim 10$ monolayers thick show a well-defined asymmetry relative to a tunnel voltage.

A study of the electrical conductivity and the electroluminescence (EL) of a planar composite consisting of gold island films and tetracene layers has revealed that EL from submicron luminescent centers is observed on a superlinear section of conduction current $I-V$ curves. The EL intensity grows with increasing voltage and becomes maximal at the CVC saturation. It is found that the EL from the nanocomposite has a 560-nm wavelength emission maximum.

\section{Introduction}

Over the last few years, semiconducting organic materials such as polycyclic aromatic hydrocarbons (tetracene, pentacene, etc.) have drawn increased attention due to their promising application in molecular electronics as an active layer for the construction of high-performance functional devices such as light emitting diodes and field effect transistors [1-4].

The attractive features of organic light emitting systems are the ease of their processing, possibility to obtain materials of high chemical purity, as well as the simplicity to construct flexible, large-area devices at low cost, by using the vacuum deposition or spin coating.

Contrary to the above-mentioned works [1-4], where the organic molecules were used as an active layer in vertically stacked devices, we proposed a new type of planar nano-sized light emitting devices consisting of a gold island film coated with an organic luminophore [5].

It is known that, while passing the electric current, the metal island film emits electrons and photons [6] capable to provide the effective energy transfer to the organic layer. Among currently investigated organic materials, tetracene $\left(\mathrm{C}_{18} \mathrm{H}_{12}, \mathrm{Tc}\right)$, the four-ringed member of the series of acenes, appears to be particularly interesting, since it can compete with amorphous silicon in terms of the field-effect mobility, and it has been already successfully applied to organic devices. Therefore, it is important to perform a systematic study of the structure and the morphology of tetracene thin films and nanocomposites used in the planar nano-sized light-emitting devices to attain a better understanding of the physical processes leading to the improvement of device performances.

\section{Materials and Experimental Methods}

Reagent grade Tc (Aldrich) was used without further purification. Thin organic and metal films were prepared by the thermal evaporation in a vacuum chamber at a pressure of $\sim 3 \times 10^{4} \mathrm{~Pa}$. Tc films were deposited simultaneously on Au-coated and clean $\mathrm{KBr}$ substrates so that the complementary Fourier transform infrared (FTIR) techniques could be employed on similar films. The thickness of the vapor-deposited (VD) organic films was controlled with a quartz balance and varied from 10 to $120 \mathrm{~nm}$. As metal substrates, two types of $\mathrm{Au}$ films were used: 1) island Au films and 2) crystalline $\mathrm{Au}$ (111) oriented films. Reflection-absorption FTIR measurements were performed on the two types of Au-coated $\mathrm{KBr}$ substrates, while FTIR transmission measurements were made on the films deposited on $\mathrm{KBr}$ samples only. The complementary measurements were performed on polycrystalline bulk Tc pressed in $\mathrm{KBr}$ pellets.

FTIR transmission and reflection-absorption (RA) spectra were measured to examine the chemical structure and the molecular orientation in the VD thin organic films. Infrared spectra of the films were measured at room temperature with a Bruker IFS-88 FTIR spectrometer in the spectral range $380-4000 \mathrm{~cm}^{-1}$. The spectra were collected at the $2-\mathrm{cm}^{-1}$ resolution, and typically 256 scans were used to record the spectra of high signalto-noise ratio. For RA measurements, a Harrick-type 


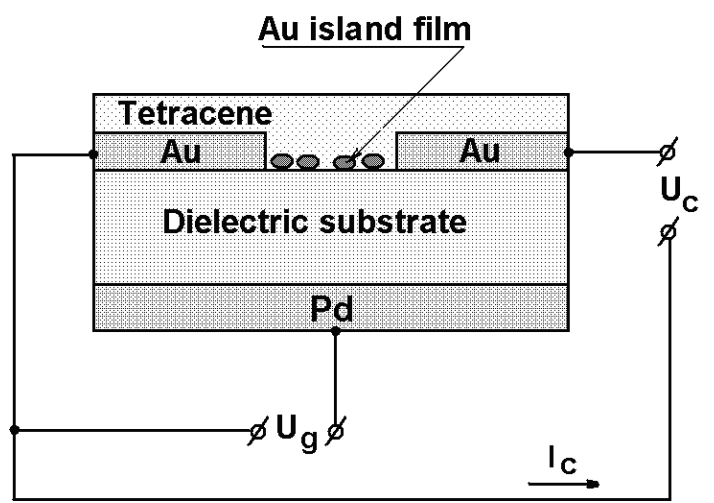

Fig. 1. Schematic of a planar gap-type cell for the measurements of electric conductivity and electroluminescence

ATR attachment was used. The IR beam was incident onto the sample plane at about $72^{\circ}$ from the surface normal.

The molecular structure and properties of thin tetracene films adsorbed on the atomically smooth surface of highly oriented pyrolytic graphite (HOPG) have been studied by scanning tunneling microscopy (STM) and scanning tunneling spectroscopy (STS). The graphite substrate was prepared by the cleaving of a corresponding single crystal. Tetracene films were obtained by the thermal vacuum deposition.

The structure of tetracene films has been studied by a commercial STM system "Solver Pro" NT MDT (Russia). Tips were prepared from a mechanically sharpened $\mathrm{Pt} / \mathrm{Ir}$ wire. STM-images have been recorded in the constant current mode with currents about of 10-600 pA and a tip bias of $100-1000 \mathrm{mV}$. Investigations were carried out under ambient conditions. The results were obtained with different samples and tips to check for the reproducibility and to ensure that results are free from artifacts.

The electronic properties have been studied by STM used in the STS operation mode. Local current-voltage $(I-V)$ characteristics were recorded at a fixed tip-sample distance corresponding to the imaging conditions (voltage, tunneling current). Upon the recording of a local $I-V$ curve, the scanning and the feedback loop were switched off. The range of the tunneling voltage was in the limit from $-1.2 \mathrm{~V}$ to $+1.2 \mathrm{~V}$.

For the studies of electric conductivity and electroluminescence, a planar gap-type cell was fabricated (Fig. 1). The cell consists of two conducting metal strips deposited on a dielectric substrate (glass, mica) and separated with a narrow $(\sim 30 \mu \mathrm{m})$ gap. By the UHV deposition method, the gap was covered with Au nanoislands and then with a tetracene thin layer. To study the in-

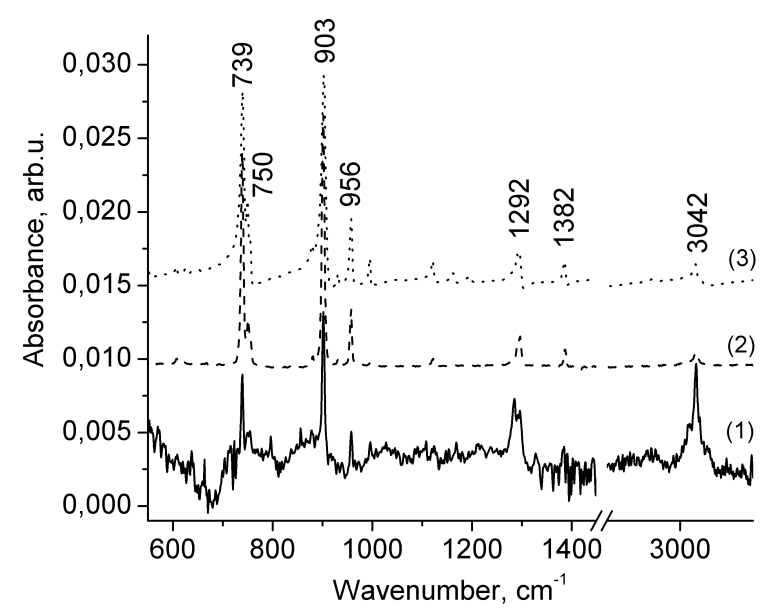

Fig. 2. Comparison of IR RA (1) and absorption spectra (2) of Tc thin films deposited on Au-precoated (1) and pure $\mathrm{KBr}$ (2) substrates against the IR absorption spectrum of polycrystalline $\mathrm{Tc}$ in a $\mathrm{KBr}$ pellet (3)

fluence of a transverse electric field on the electric characteristics and EL, the nanocomposites were prepared on a thin $(\sim 3 \mu \mathrm{m})$ mica substrate with a gate Pd electrode deposited onto its back side (Fig. 1). The samples were mounted into the vacuum chamber equipped with a glass window. The EL and electric conductivity measurements were carried out in vacuum $\left(\sim 10^{-4} \mathrm{~Pa}\right)$. The $I-V$ characteristic of a conduction current, as well as the lux-voltage and spectral characteristics of the samples, were measured and processed with a help of a homemade computer-controlled experimental setup.

\section{Experimental Results and Discussion}

\subsection{FTIR spectroscopy}

The chemical structure and the molecular orientation in VD thin organic films were evaluated with the help of IR spectroscopy. In Fig. 2, the IR reflection-absorption (RA) spectrum of Tc thin films deposited by the thermal evaporation in vacuum on the Au-precoated $\mathrm{KBr}$ substrate (curve 1) is compared with the IR absorption spectra of Tc thin films deposited on the $\mathrm{KBr}$ surface in vacuum (curve 2) and polycrystalline Tc (curve 3). As one can see from Fig. 2, all three spectra are very similar and exhibit the main characteristic vibrational modes of a Tc molecule, thus indicating that, at a thickness of about $100 \mathrm{~nm}$, the deposited thin films show no evidence for impurities or degradation of the initial substance during the thermal evaporation in vacuum and consist only of the unchanged Tc compound. At the same time, it should be noted that we obtained no sufficiently good 
transmission spectra of Tc layers deposited onto Au islands due to the extremely small thickness of a film and the poor signal-to-noise ratio.

The spectral parameters (peak position and intensity of fundamental vibration bands) of polycrystalline Tc were used as a reference for the assignment of the FTIR spectra of Tc thin layers deposited onto various substrates. A Tc molecule is flat and consists of four elongated $\pi$-conjugated aromatic benzene-like rings joined sideways along the long molecular axis. Its bulk phase has the same triclinic crystal symmetry as pentacene [7] with two molecules per unit cell. Tc molecules in the crystal lattice form a layered structure along $\langle 001\rangle$ direction [8]. The long molecular axes of all molecules within the unit cell are oriented in parallel to each other, whereas the adjacent molecular planes are tilted, which form the typical herringbone structure of Tc. The bonds between molecules in the same layer ( $a b$-plane) are several times stronger than those between molecules in adjacent layers. When deposited on a substrate, with which Tc interacts weakly, such anisotropy in the molecular interaction should result in a self-organized highly crystalline layers with the "standing-up" molecular orientation. The harmonic vibrational mode frequencies of tetracene were determined from $a b$ initio calculations using the density functional theory in $[9,10]$ and the Gaussian98 program. From these results, it was possible to assign all of the experimental spectral features in the FTIR and Raman spectra to specific intramolecular vibrational modes of a tetracene molecule. The vibrational modes can be classified into two generic categories relative to the plane defined by the aromatic rings of a molecule: vibrations with atomic displacements parallel to the plane of the tetracene molecule (in-plane vibrations) and those with atomic displacements perpendicular to the plane of tetracene molecules (out-of-plane vibrations). The transition dipole moment for the in-plane vibrational modes is directed in parallel to the plane of the Tc molecules, while, for the out-of-plane modes, it is directed perpendicularly to this plane. It is commonly accepted to subdivide the vibrational spectra of complex molecules into different spectral ranges corresponding to different types of vibrational modes. In the experimental IR spectrum of initial polycrystalline Tc, two groups of bands with substantial intensity can be seen (Fig. 2). The highfrequency region $\left(3600-2700 \mathrm{~cm}^{-1}\right)$ contains the absorption bands mainly originating from localized symmetric and asymmetric in-plane stretching vibrations of aromatic $\mathrm{CH}$ groups (weak absorption bands centered at 3016 and $\left.3047 \mathrm{~cm}^{-1}\right)$. The mid-frequency region
(1700-1000 $\left.\mathrm{cm}^{-1}\right)$ corresponds to in-plane CC stretching and $\mathrm{CH}$ bending vibrations. In the low-frequency region (below $1000 \mathrm{~cm}^{-1}$ ), the out-of-plane and torsional modes are observed. These are the absorption bands of out-of-plane $\mathrm{CH}$ vibration bands centered at 739 and 750,880 and $903 \mathrm{~cm}^{-1}$, as well as the weak absorption bands of benzene rings $\mathrm{CC}$ stretching vibrations centered at 1464,1536 , and $1629 \mathrm{~cm}^{-1}$. It also worth mentioning a doublet structure observed for the major absorption bands in the FTIR absorption spectra of polycrystalline Tc, which is induced by the factor group splitting of vibrational modes in the crystal.

As follows from the comparison of FTIR spectra of Tc thin films and bulk polycrystalline Tc (Fig. 2), all three spectra are very similar and exhibit the main characteristic vibrational modes of polycrystalline Tc, by indicating that the deposited layers contain only the unchanged Tc compound. The factor group splitting recorded for $\mathrm{CH}$ bending modes (the doublets at 739$750 \mathrm{~cm}^{-1}, 903$, and $1292 \mathrm{~cm}^{-1}$ ) suggests a highly ordered crystalline structure of the deposited layers. At the same time, as is seen from Fig. 2, the peak intensities for particular bands, e.g., the bands centered at 739, 903, and $3042 \mathrm{~cm}^{-1}$ are different in the transmission and RA spectra (Fig. 2, curves 1 and 2). Most pronounced changes in the intensity and the line shape are observed for the vibrational modes which have a contribution from $\mathrm{CH}$ bending and stretching vibrations. In the RA spectra of VD films, the intensity of the out-of-plane $\mathrm{CH}$ bending vibration band at 739 and $903 \mathrm{~cm}^{-1}$ with transition dipoles perpendicular to the Tc molecule plane is lower as compared with the transmission spectra of Tc. To the contrary, the intensity of the in-plane $\mathrm{CH}$ stretching vibration band observed at $3042 \mathrm{~cm}^{-1}$, with the transition dipole parallel to the plane of Tc molecule, is higher. Reflection absorption (RA) infrared spectroscopy is commonly used to study the orientation of thin films deposited on a reflecting metal substrate. It should be noted that the electric field of IR radiation in the transmission measurements is directed in parallel to the film surface, whereas, in the RA measurements, it is normal to the film surface allowing one to determine the average molecular orientation by comparing the relative experimental band intensities. According to the surface selection rule in IR RA spectroscopy, the vibrational modes with their transition moments perpendicular to the surface of a substrate are enhanced in a RA spectrum. In the transmission spectrum, on the other hand, the strong peaks originate from the vibra- 
tional modes with their transition moments parallel to the surface of a substrate. It is well known that the transition moments of $\mathrm{CH}$ stretching modes of benzene rings are parallel to the benzene ring plane. Thus, the observed differences indicate that, on the both studied substrates, clean or $\mathrm{Au}$-precoated $\mathrm{KBr}$, the orientation of Tc molecules in the VD thin film should have a "standing-up" perpendicular orientation relative to the substrate.

Since our measurements of the FTIR spectra of Tc superthin layers deposited on the $\mathrm{KBr}$ or island $\mathrm{Au}$ surface failed due to a subtle intensity of the spectra and a high noise level, it was impossible to draw reliable conclusions concerning the molecular orientation and the structure of such extra-thin layers. Therefore, the STM measurements were carried out to get additional data on the structure and electronic properties of extra-thin VD films of Tc.

\section{2. $S T M / S T S$ studies of tetracene films}

The STM-image of a tetracene thin film of 1-3 monolayers (ML) in thickness deposited on the atomically flat HOPG substrate revealed an amorphous structure. Since deposited tetracene films were disordered, the molecular resolution could not be achieved.

The recorded local $I-V$ curves of $\sim 10$-ML-thick tetracene films shown in Fig. 3 are asymmetric. It is shown that the electrical conductivity of the Tc film is $\sim 3$ times greater at a negative voltage than at the corresponding positive voltage. The reason for the observed asymmetry can be explained by an asymmetry of the electron transport at the Tc/substrate interface. Since, at a negative voltage applied to the sample, the electrons move out of the film toward the tip, the observed high electron conductivity cannot be attributed to the field emission. In addition, the voltage-current characteristic measured between the pure substrate and a $\mathrm{Pt} / \mathrm{Ir}$ tip is symmetric. After the deposition of a tetracene film, the tunneling gap can be considered as a double interface consisting of the graphite-aromatic junction and the aromatic-tip junction. We assume that the asymmetry is due to the graphite-aromatic junction which is confirmed by our qualitative analysis. Thus, the asymmetry of $I-V$ curves is due to the presence of a Tc layer on the graphite substrate. One cannot exclude that the asymmetry is due to a certain orientation of Tc molecules with respect to the substrate and due to a specificity of the electron structure of the Tc/substrate interface.

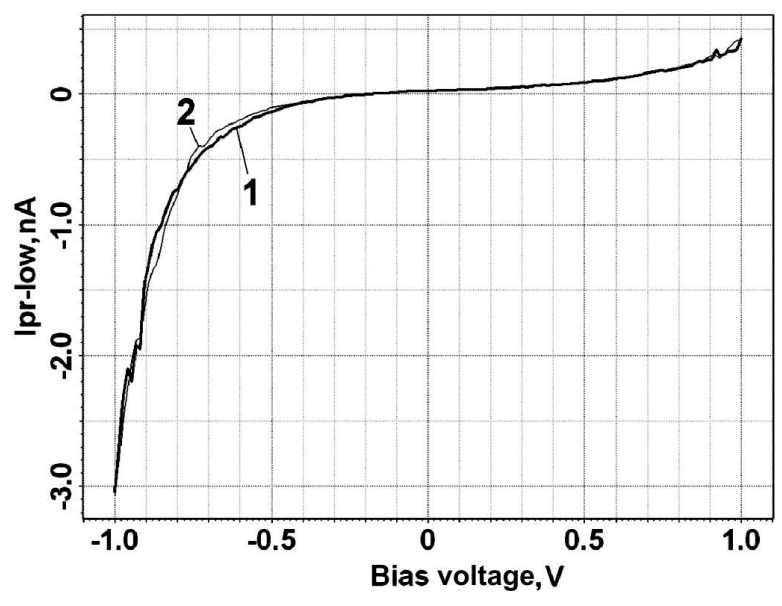

Fig. 3. Local current-voltage $(I-V)$ characteristic of a Tc monolayer measured in the STS mode at voltage increasing (1) and decreasing (2) cycles

\subsection{Electroconductivity and electroluminescence of the nanocomposite}

After the fabrication of a nanocomposite sample consisting of gold nanoparticles coated with a tetracene layer (Fig. 1) and its arrangement in a vacuum chamber, the sample was subjected to an electroforming procedure to obtain EL. It is known [6] that, in planar systems of such type, the applying of a voltage results in the formation of current channels due to the percolation processes with the subsequent formation of submicron luminescence centers (so-called "emission centers") in the majority of channels. When the applied voltage increases, the luminescence intensity from such centers grows, and the emergence of new emission centers is observed.

In the gold-tetracene nanocomposite, the effective formation of luminescence centers and an increase in their number take place at low values of the applied voltage due to a high mobility of Tc molecules.

The $I-V$ characteristic of the conduction current measured on the nanocomposite after the electroforming procedure is typical of organometallic nanocomposites [11]. The $I-V$ curve is linear in the low-voltage region and then becomes superlinear. The further increase of the applied voltage results in a saturation or even a decrease of the conduction current (Fig. 4). The EL from the sample appears at a superlinear section of the $I-V$ curve and increases in the regions of the conduction current saturation or the current decrease.

The EL spectrum measured for the nanocomposite has a maximum at $560 \mathrm{~nm}$. Its position is somewhat shifted toward the long-wave region as compared with the EL 


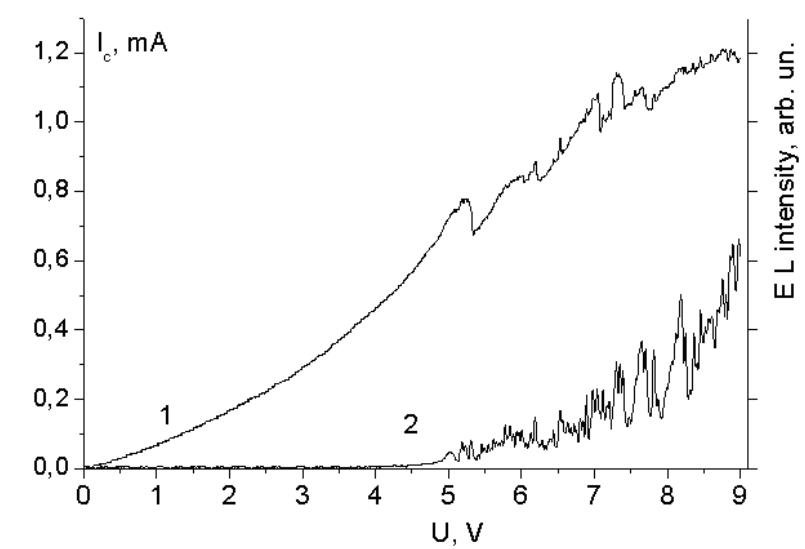

Fig. 4. Current-voltage $(I-V)$ characteristic of a conduction current (1) and the lux-voltage characteristic of EL (2) from the Tc$\mathrm{Au}$ nanoislands nanocomposite

spectrum given in [4], where EL of Tc films was studied, and the spectral maximum was found to be at $540 \mathrm{~nm}$. In our measurements, the EL spectra reflect not only EL of tetracene, but EL from Au nanoislands themselves (the spectral maximum at 530-590 nm) as well [6]. EL can be caused by the plasmon-mediated mechanism. Such a superposition of the spectra can be a reason for the observed shift of the maximum position of the EL spectra of the nanocomposite.

Simultaneously with EL, the electron emission from the emission centers was observed [6]. It is possible to suggest that EL from the nanocomposite may originate from the excitation of organic molecules by emitted electrons.

As shown by our experiments, the $I-V$ curve asymmetry is observed not only for local $I-V$ curves in STS studies, but also for the planar light-emitting nanostructures consisting of gold nanoparticles and tetracene molecules in the linear region of the integral $I-V$ curves of the conduction current after the change of the applied voltage polarity. The asymmetry occurs for structures working for a long time at the same polarity of the applied voltage. It can be caused by a certain orientation of the mobile Tc molecules in the strong electric field which is present in the region of emission centers [6]. These experiments should be continued to elucidate the observed effect.

For the samples prepared on a thin mica substrate, the study on the influence of a transverse electric field on the electric characteristics and EL was carried out. In such a system at the time moment of applying the voltage to the gate Pd electrode (Fig. 1), the conduction current and the luminescence intensity are sharply drop. But then they gradually return to their original values regardless of whether the voltage is retained at the gate all the time or switched-off.

\section{Conclusions}

With the help of FTIR spectroscopy, it is shown that the molecular structure in Tc thin films vacuum-deposited on clean and $\mathrm{Au}$-precoated $\mathrm{KBr}$ substrates corresponds to the molecular structure of bulk Tc. These results show that Tc thin films can be used as an organic component in planar light-emitting structures.

The STM/STS investigation of tetracene films deposited on atomically smooth highly-oriented pyrolytic graphite has shown that the films are disordered. It has been found that the local $I-V$ curves of $\sim 10-\mathrm{ML}$ tetracene films are asymmetric. The asymmetry is explained by the specificity of the electron structure of the tetracene film/substrate interface.

Studies of the electrical conductivity and EL of a planar nanocomposite consisting of gold island films and tetracene layers show that the EL emission from submicron luminescent centers is observed in a superlinear part of the $I-V$ characteristics of the conduction current. The EL intensity grows with the voltage and reaches its maximum at the $I-V$ curve saturation. It is found that EL from the nanocomposite has a $560-\mathrm{nm}$ wavelength emission maximum.

These results show that Tc can be prospective material for the use in planar light-emitting nanocomposites.

The authors remember with thanks the collaboration with prof. G.O. Puchkovska who initiated the IRspectroscopy investigations of organo-metallic nanocomposites in the Institute of Physics of NAS of Ukraine. The financial support from the State Agency for Science, Innovations and Informatization of Ukraine under the Ukrainian-Russian Scientific Cooperation Program on nanotechnology (project $\mathrm{M} / 213-2011$ ) is gratefully acknowledged.

1. H.-S. Seo, M.-J. An, Y. Zhang, and J.-H. Choi, J. Phys. Chem. C 114, 6141 (2010).

2. C. Santato, I. Manunza, A. Bonfiglio, F. Cicoira, P. Cosseddu, R. Zamboni, and M. Muccini, Appl. Phys. Lett. 86, 141106 (2005).

3. C. Santato, R. Capelli, M.A. Loi, M. Murgia, F. Cicoira, V.A.L. Roy, P. Stallinga, R. Zamboni, C. Rost, S.F. Karg, and M. Muccini, Synth. Met. 146, 329 (2004).

4. A. Hepp, H. Heil, W. Weise, M. Ahles, R. Schmechel, and H. von Seggern, Phys. Rev. Lett. 91, 157406 (2003). 
5. T. Gavrilko, R. Fedorovich, G. Dovbeshko, A. Marchenko, A. Naumovets, V. Nechytaylo, G. Puchkovska, L. Viduta, J. Baran, and H. Ratajczak, J. Mol. Str. 704, 163 (2004).

6. R. Fedorovich, A. Naumovets, and P. Tomchuk, Phys. Rep. 328, 73 (2000).

7. G. Filippini and M. Gramaccioli, Chem. Phys. Lett. 104, 50 (1984).

8. R.B. Campbell, J.M. Robertson, and J. Trotter, Acta Crystallogr. 14, 705 (1961); R.B. Campbell and J.M. Robertson, Acta Crystallogr. 15, 289 (1962).

9. S.R. Langhoff, J. Phys. Chem. 100, 2819 (1996).

10. M. Malagoli, V. Coropceanu, D.A. da Silva Filho, and J.L. Bredas, J. Chem. Phys. 120, 7490 (2004).

11. D.A. Chubich, R.D. Fedorovich, and A.G. Vitukhnovsky, J. of Russ. Laser Res. 29, 368 (2008).

Received 21.09.11
СТРУКТУРА ТА ЕЛЕКТРОЛЮМІНЕСЦЕНТНІ

ВЛАСТИВОСТІ ТОНКИХ ШАРІВ ТЕТРАЦЕНУ НА ОСТРІВЦЕВИХ ПЛІВКАХ ЗОЛОТА

Л. Відута, Т. Гаврилко, А. Марченко, В. Нечитайло, А. Сененко, Р. Федорович, П. Шабатін

$\mathrm{P}$ е $з$ ю м е

За допомогою ІЧ-спектроскопії, а також СТМ/СТС методик досліджено молекулярну структуру, морфологію та електропровідність тонких шарів тетрацену, отриманих термічним напорошенням у вакуумі. Показано, що такий метод приготування не змінюе молекулярну структуру тетрацену. Тонкі шари тетрацену на атомно-гладкій поверхні піролітичного графіту мають аморфну структуру, а локальні ВАХ, виміряні для плівок тетрацену товщиною $\sim 10$ моношарів, мають чітко виражену асиметрію відносно полярності тунельної напруги.

Дослідження електропровідності та електролюмінесценції (ЕЛ) планарного композита, який складався з острівцевих плівок золота та плівок тетрацену, показали, що ЕЛ центрів субмікронного розміру спостерігається на нелінійній ділянці BAX

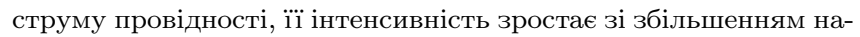
пруги та досягає максимуму у області насичення BAX. Спектр випромінювання має максимум у області 560 нм. 